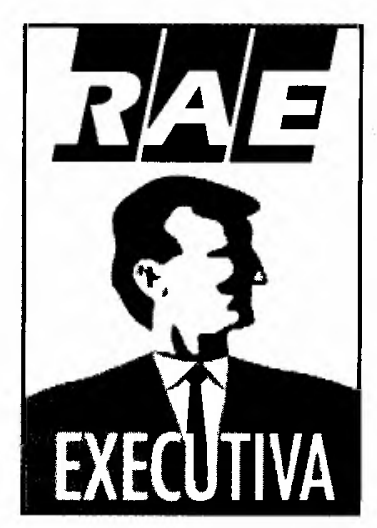

\title{
PRIVATIZAÇÃO DO SETOR \\ ELÉTRICO: DE VOLTA AO FUTURO \\ OU UM PASSO PARA O PASSADO?
}

*Sergio Augusto Weigert Ennes

Qual deve ser o papel do capital privado no modelo institucional do Setor Elétrico?

What should be the function of private capital in the institutional model of Power Sector?

PALAVRAS-CHAVE:

Planejamento energético, politicas públicas, privatização, Setor Elétrico, legislą̧ão, modelo institucional, desenvolvimento econômico história do Setor Elétrico, desregulamentação, deses. tatização.

\section{KEY WORDS:}

Energy Planning, public policy, prlvatization, Power Sector, legislation, institutional model, economic development, Power Sector history, unregulation.
*Mestrando na Faculdade de Engenharla Mecânica da UNICAMP e Funcionário do Departamento de Planejamento da CESP.
A privatização dos serviços públicos de energia elétrica tem ocupado grande espaço na imprensa e representa um dos assuntos mais discutidos nos últimos anos. Entretanto, ainda não foi estabelecido um modelo que atenda simultaneamente aos interesses dos consumidores, dos atuais detentores das concessões e dos potenciais investidores. A discussão desse modelo arrasta-se desde a promulgação da Constituição de 1988 e ainda se caracteriza pelas posições não-convergentes dos vários agentes e interesses envolvidos.

O objetivo deste artigo é discutir algu-

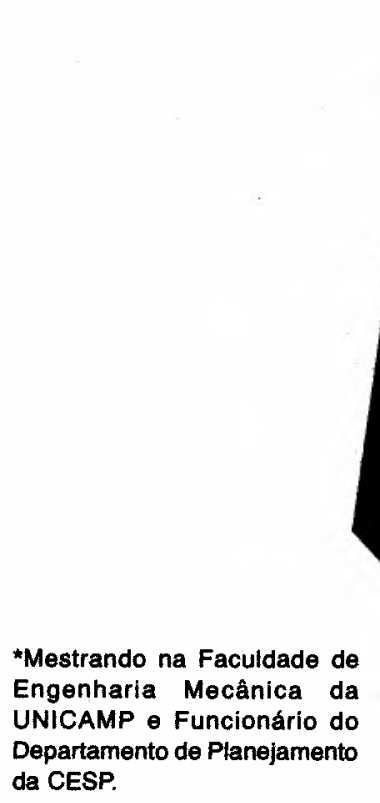

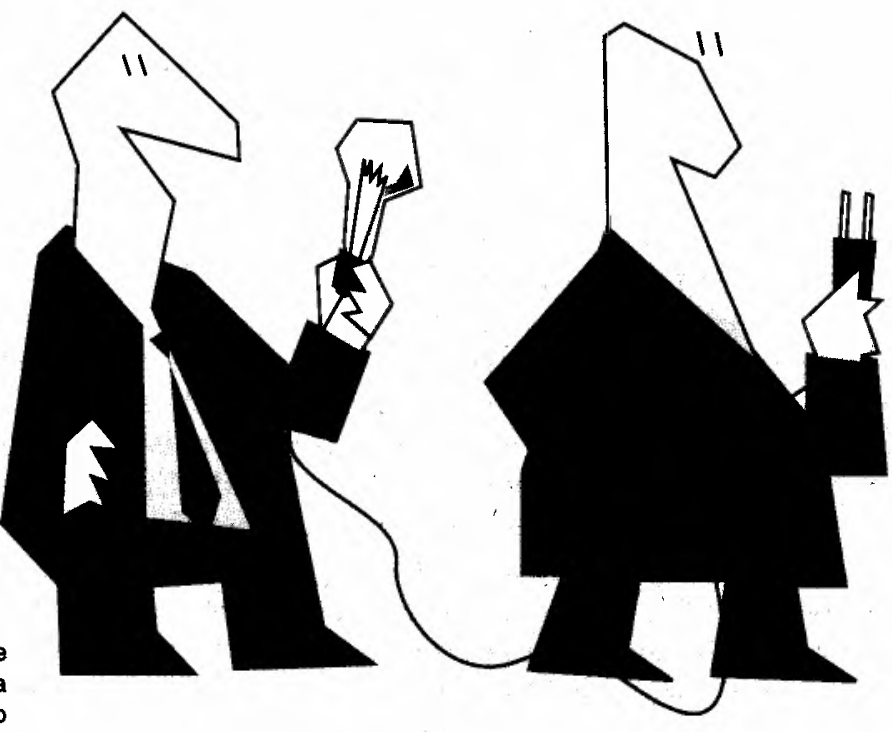

São Pauio, v. 35, n.1, p. 17-22

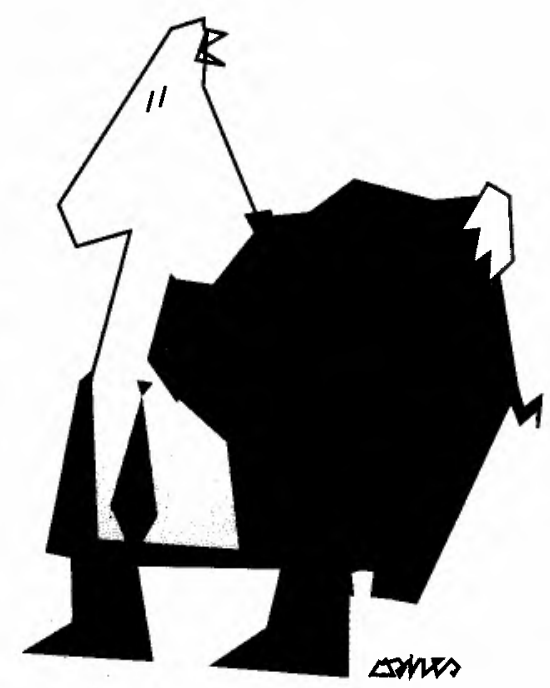

Mar./Abr. 1995 
Na década de 90 ,

iniciaram-se profundas

reformas visando a

reestabelecer as

condições para a

retomada do

crescimento

econômico, que

ainda depende da

regulamentação do

artigo $175 \mathrm{da}$

Constituição

Federal promulgada

em 1988.
A partir dos anos 50, o desenvolvimento econômico se acelera passando a exigir grandes investimentos em infra-estrutura. As empresas estrangeiras, no entanto, não estavam dispostas a efetuá-los. Assim, iniciou-se a evolução de um sistema essencialmente privado para um modelo estatal, onde a União controlava a oferta, a transmissão e grande parte da distribuição por meio de empresas concessionárias de serviços públicos. O modelo construído para esse setor apresentava as seguintes características básicas:

- empresas estatais de âmbito nacional, regional e estadual;

- decisóes centralizadas;

- preços e tarifas equalizados, enfatizando efeitos socioeconômicos globais;

- necessidade de menor controle e regulamentação do que o sistema de concessão às empresas privadas.

Com a criação da ELETROBRÁS (Centrais Elétricas Brasileiras), em 1961, processou-se a formação do setor elétrico como está organizado atualmente, com constituição das empresas estaduais, em geral responsáveis pela distribuição, enquanto as subsidiárias da ELETROBRÁS-FURNAS (Centrais Elétricas Furnas), CHESF (Companhia Hidroelétrica do São Francisco) e mais tarde ELETROSUL ( Centrais Elétricas do Sul do Brasil) e ELETRONORTE (Centrais Elétricas do Norte do Brasil), seriam responsáveis pela construção das usinas geradoras.

$\mathrm{Na}$ prática, o modelo empresarial do setor constituiu-se em um sistema híbrido, parcialmente centralizado, de empresas federais e estaduais, cujo relacionamento sempre foi foco de conflitos, em especial a respeito da concessão dos potenciais a serem explorados e da repartição dos fluxos financeiros intra-setoriais.

$\mathrm{Na}$ década de 70 , foram concluídas as principais hidrelétricas previstas nos estudos da CANAMBRA (Consórcio de Empresas Consultoras Canadenses, Americanas e Brasileiras) e foi iniciada a construçáo de Itaipu. Essa usina introduziu nova e importante fonte de conflito no setor, à medida que a aquisição compulsória da sua energia foi imposta pelo Governo Federal às empresas estaduais.
1. BIBLIOTECA DO EXÉRCITO. da primeira lâmpada à Eletrobrás, Rio de Janeiro, 1978. 
Os anos 80 significaram a progressiva desestruturação do setor, provocada pela ação conjugada dos seguintes fatores:

- crise da dívida externa, que eliminou a principal fonte de financiamento do setor;

- descentralização das decisões, sem a existência de regulamentação adequada;

- política tarifária irrealista;

* ruptura dos fluxos financeiros do setor, conduzindo-o a uma situação caótica;

* completa omissão do poder concedente do DNAEE (Departamento Nacional de Águas e Energia Elétrica), em relação às suas funções de fiscalização e regulamentação.

Na década de 90, iniciaram-se profundas reformas visando a reestabelecer as condições para a retomada do crescimento econômico, entre as quais cabe destaque e prioridade à forma de concessão e permissão para explorar serviços públicos, que ainda depende da regulamentação do artigo 175 da Constituição Federal promulgada em 1988. Neste contexto, ganha relevo o atual debate sobre a privatização.

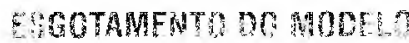

Talvez as notícias mais divulgadas pela imprensa, sobre o setor, refiram-se à quantidade de obras paralisadas e aos custos exorbitantes de algumas delas. Com efeito, vários motivos contribuíram para essa situação que, felizmente, não atinge igualmente a todas as empresas, evidenciando que existe uma parcela importante que deve ser debitada à má gestão das empresas públicas. A má gestão inclui erros grosseiros de planejamento e falta de responsabilidade dos decisores que anunciaram sistematicamente riscos de escasse $z$ de energia para justificar a "necessidade" de novas obras, sem haver garantia de recursos financeiros para implementá-las.

As magnitudes das demandas sobre-estimadas podem ser avaliadas, no gráfico $1^{2}$, no qual se verifica que em 1986 supunha-se que o consumo nacional seria 420.000 GWh (GigaWatthora) no ano 2000, enquanto em 1991 previa-se somente 341.000 GWh para o mesmo ano, impli-
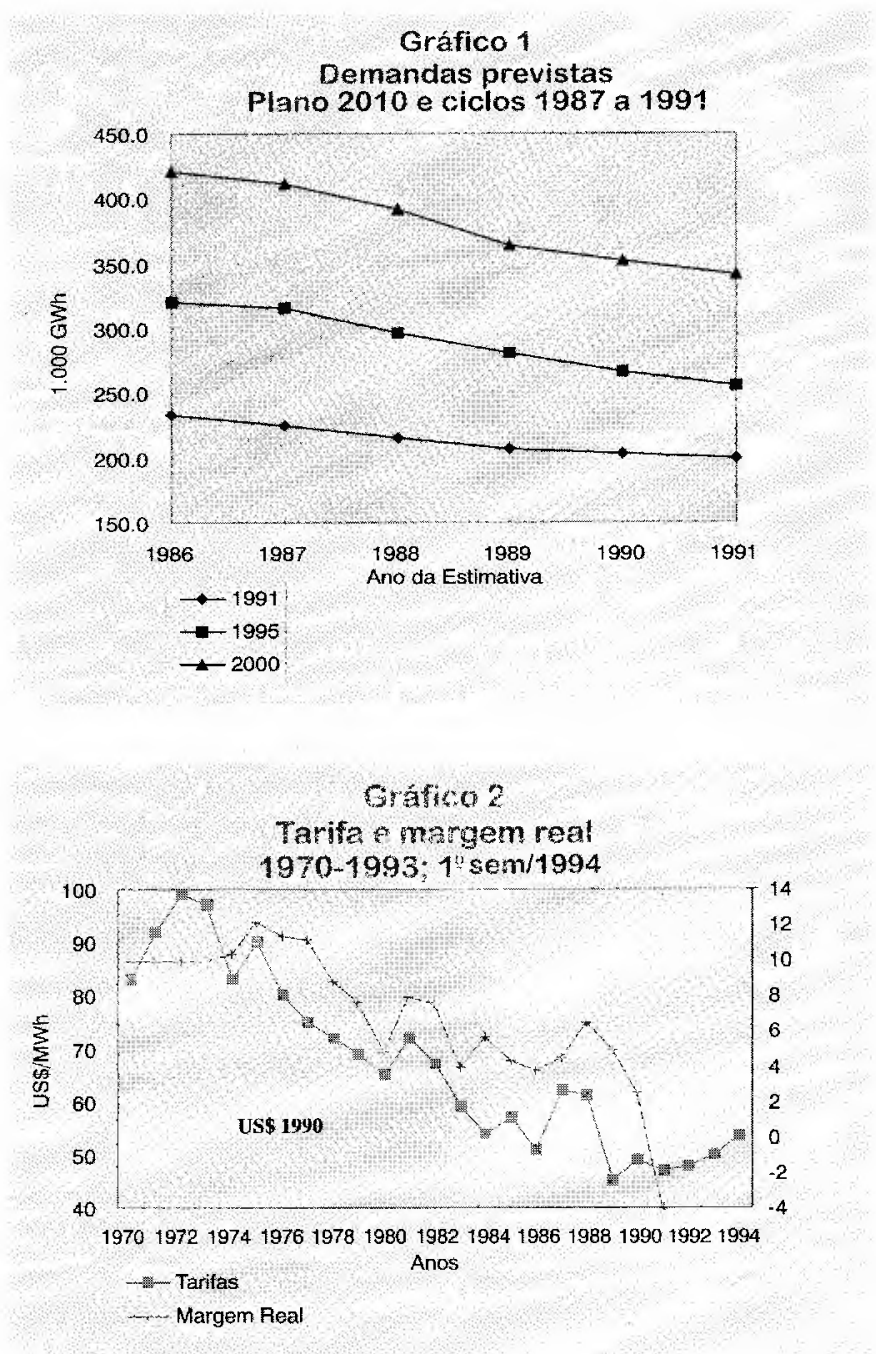

cando uma redução equivalente a 20.000 MW de novas usinas apenas no período de seis anos.

Em 1986, também considerava-se provável consumir $233.900 \mathrm{GWh}$ em 1991, sendo que o consumo efetivo foi de apenas $200.000 \mathrm{GWh}$, diferença equivalente a uma capacidade de $8.600 \mathrm{MW}$ em nível nacional, dos quais $4.800 \mathrm{MW}$ localizados na região Sudeste. Nesse caso, o efeito do sobre-investimento foi mais grave, pois as obras necessárias para atender àquela demanda já estavam em construçāo e foram paralisadas por falta de recursos financeiros.

\section{Colapso financeiro}

Ao lado da má gestāo de algumas empresas importantes do setor, as desastrosas políticas de controle das tarifas públicas contribuíram para a redução das dis-
2. PLANO NACIONAL DE ENERGIA ELĖTRICA 2010 - PLANO 2010, Rio de Janeiro, Eletrobrás, 1987. 


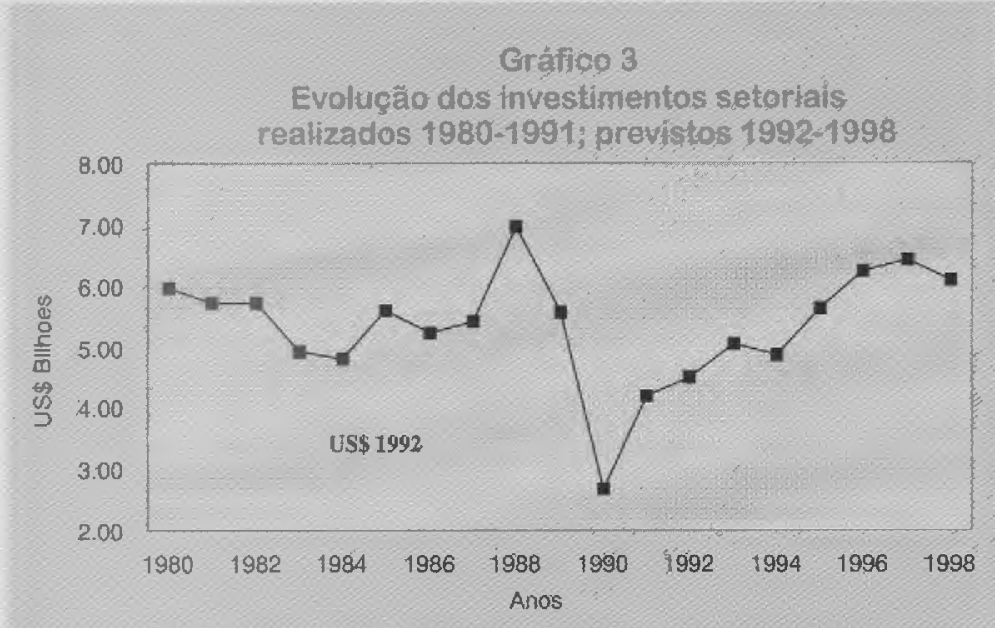

3.PLANO NACIONAL DE ENERGIA ELÉTRICA 1993-2015 PLANO 2015 "PROJETO 8 A Questão Econômico-Financeira" Rio de Janeiro, Eletrobrás, 1994.

4. PLANO NACIONAL DEENERGIA ELETRICA 1993-2015 PLANO 2015 "PROJETO 8 A Questão Econômico-Financeira", Versāo Preliminar, Rio de Janeiro, Eletrobrás, 1994.

5. Idem, ibidem ponibilidades para investimento. Assim, a situação financeira do setor agravou-se continuamente, com a deterioraçấo dos principais indicadores de resultados.

O comportamento da taxa de retorno sobre o investimento ${ }^{3}$ sintetiza a realidade das empresas de energia elétrica. Esse indicador apresenta uma tendência declinante durante a década de 80 , alcançando niveis sistematicamente abaixo da taxa média de juros ( $9 \%$ a.a.). A remuneração dos investimentos declinou de $12,1 \%$, em 1975, para 5,1\%, em 1985, e em 1989 tornou-se negativa ou próxima a zero, conforme ilustra-se no gráfico 2 , onde indicase também a evolução do valor real da tarifa média percebida pelo setor.

É evidente que ocorred a deterioração das receitas tarifárias, pois o valor real da tarifa média passou de US\$ 83 por MWh na década de 70 , para US\$ $\$ 5$ por MWh na década de 80 , enquanto que nos últimos anos foram praticadas tarifas médias abaixo de US $\$ 50$ por $M W h$. A remuneração obtida pelo setor, que nāo atinge a mínima legal de $10 \%$ desde 1977, após 1988 caiu 1991, segundo relatório da Eletrobrás .

\section{A crise dos investimentos}

Não resta dúvida que os principais indicadores financeiros também evidenciam o colapso da capacidade de investimento das empresas públicas. Durante us anos 80 ocorreu uma redução drástica da geração interna de recursos financeiros, que em 1991 alcançou apenas US\$ 3,97 bilhōes, equivalentes a $35 \%$ da necessidade total, de $6 \%$ para estimados $4 \%$ negativos em de US\$ 11,4 bilhōes. Para dar continuidade ao programa de investimento de US\$ 4,5 bilhóes, modesto face às necessidades futuras, e arcando com um serviço da dívida equivalente a US\$ 6,9 bilhões, seria preciso obter novos financiamentos de US\$ 7,43 bilhōes 5 .

Isso demonstra de forma definitiva que o processo de descapitalização pelo qual o setor atravessou persiste, malgrado as sucessivas promessas realizadas pelo poder concedente de recuperar o valor real das tarifas; de forma que os investimentos têm sido quase completamente financiados com recursos de terceiros. Com efeito, o autofinanciamento do setor declinou, no Brasil, entre 1980 e 1989 , de $29 \%$ para apenas $8 \%$.

A partir de 1988, com o descumprimento das metas tarifárias estabelecidas no Programa de Recuperação Setorial (PRS) negociado com o sistema Banco Mundial/ Banco Interamericano de Desenvolvimento, os investimentos caíram rapidamente (ver gráfico 3), pois essas instituiçōes, que eram a principal fonte externa de financiamento do setor, interromperam seus fluxos de recursos. Os investimentos médios, que alcançaram US $\$ 4,7$ bilhốes de 1980 a 1988, passaram a US $\$ 3$ bilhões em 1990 e a US\$ 4 bilhões em 1991.

\section{PRIVATIZACÃO OU COMPETIÇÃO?}

A questão da privatização está para a discussão dos problemas econômicos nacionais como as panacéias de planejamento estratégico estão para as empresas privadas: uma "solução mágica" rumo à eficiência e à competitividade.

A privatização tem sido apresentada como a solưção para atração de novos recursos financeiros para o setor, representando uma completa inversão dos argumentos que justificaram a estatizaçắo durante os anos 50 . E qual a perspectiva em 1995 para o aporte de capitais para o setor energético? Após o fracasso da "Modernidad" mexicana, os investidores internacionais tornaram-se muito cautelosus com us países latino-americanos e apenas a estabilidade econômica, associada a uma mudança radical no marco jurídicoinstitucional, poderá alterar esse comportamento. 
De qualquer forma, a privatização de parcela dos investimentos, isoladamente, nāo contribuirá de forma decisiva para a reestruturação do setor. Sem embargo, o essencial é a definição de um novo modelo institucional que substitua o já desgastado "serviço pelo custo".

Na realidade, a questão subjacente à da privatização é a da gestão das empresas públicas, que năo tem sido pautada pela obtenção de resultados. De fato, nas empresas públicas o importante náo é o lucro e sim a despesa. Os problemas de gestão, tanto macropolítica de preços, quanto micro-má administração, inviabilizaram a obtenção de financiamentos com custo e prazo compatíveis com os empreendimentos energéticos.

Assim, os problemas reais a serem equacionados são: a. novas formas de financiamento para a expansão da oferta de energia elétrica; $b$. reestruturação da gestão do setor, tanto em nível macro, quanto micro.

Cabe perguntar, então, quais formas de privatização podem dar respostas eficientes para essas questōes?

O paradigma do monopolio natural que serviu de base para a legislação reguladora no século $X X$ está sendo superado pelas novas formas que o setor elétrico vem adquirindo, com estruturas organizacionais capazes de introduzir competição onde antes parecia impossível. É importante ressaltar que pode haver competição com propriedade estatal e não haver com completa privatização. O que introduz competição não é a origem do capital e sim o desmantelamento das estruturas monopolísticas no setor, que são co-responsáveis pelos fracassos.

\section{Como privatizar}

$A$ incorporação de capitais privados aos investimentos do setor elétrico pode se realizar de diversas formas. A mais simples é a implantação de unidades de geração de propriedade de investidores privados, os chamados produtores independentes de energia elétrica. No entanto, mesmo essa forma exige uma regulamentação específica para dar garantias aos investidores. Além disso, não há clara definição de quem compraria a energia produzida, se consumidores interessados ou empresas públicas. No primeiro caso, não há estímulo aos investidores, pois as tarifas industriais estão em níveis muito baixos (entre US\$ $30 \mathrm{e}$ 35 por $\mathrm{MWh})^{6}$. No segundo, ocorre o mesmo fenômeno, pois as tarifas de suprimento entre empresas concessionárias estấo ao redor de US\$20 a 30 por MWh, tornando anti-econômicos quaisquer investimentos privados.

Convém lembrar, porém, que, nos úlimos anos, em decorrência da capitalizaçáo das empresas americanas de energia elétrica e do desenvolvimento dos IPP (Independent Power Producer), 0 interesse de investidones privados nesse ramo cresceu, como pode ser avaliado pela sua forte participaçáo na expansáo de capacidade de geração prevista $(884 \mathrm{GW})$, para serimplantada no mundo até 2003. Desse total, cerca de $34 \%$ pertence a produtores independentes, claro indicativo que há, atualmente, capitais disponíveis para esse ramo de negócio inclusive para a América Latina 7 (ver artigos publicados divulgando as oportunidades de investimento na regiäo ${ }^{8}$ ).

A participação desses capitais na expansão da geração terá implicaçóes em diferentes níveis, pois pela sua agilidade poderão evitar escassez na oferta a partir de $1999 / 2000$. Por outro lado, as taxas de remuneração pretendidas de 20 a $25 \%$ sobre o capital próprio acarretarão um aumento no custo marginal de expansáo que não deve ser ignorado, com possiveis repercussōes nas tarifas.

No caso das privatizações das empresas, na Inglaterra e na Argentina, verificou-se um aumento das tarifas para as grandes indústrias, no primeiro caso, e, no segundo, um aumento generalizado para todos os segmentos de consumo.
6. BALANCCO ENERGÉTICO NACIONAL, Ministério das Minase Energia, Brasllia, 1994.

7. BURR, M. T. Survival of the strategist. Independent Energy, Oct. 1994.

8. MEADE W., POIRIER J. L. Going global, Independent Eneroy, Sept. 1992; BURR, M. $T$. Sucess in South America. Independent Energy, June 1994: ALBISETTI R., CARTELOS T. Global power reform. Independent Energy, Jan.1994. 
No caso inglês, exemplo de privatização total já consolidada, o processo envolveu dez anos para se completar e implicou a reestruturação completa do setor: a. segmentação da antiga CEGB (Central Electricity Generation Board) em três empresas, sendo duas privadas e uma pública - responsável pelas usinas nucleares; b. criação de uma empresa responsável pelo sistema de transmissão; $c$. criação de diversas empresas de distribuiçáo regional e local.

$\mathrm{Na}$ Argentina, realizou-se processo semelhante, com a privatização da geração e da distribuição, com a diferença que o sis-

A complexa estrutura

de propriedade do setor

coloca a exigência de

um organismo regulador competente e com

poder de controlar os

poderosos agentes

envolvidos, protegendo

o interesse público.

tema argentino estava praticamente sucateado quando ocorreu a privatização. Isso exigiu elevados investimentos na recuperação e ampliação das instalaçóes de geração, transmissão e distribuição de eletricidade, que foram realizados segundo critérios privados de remuneração do capital, isto é, taxas de retorno de $20 \%$ a. a., em vez de usuais taxas de $10 \%$ utilizadas pelo setor público.

No caso brasileiro, uma possibilidade concreta é a abertura para novos agentes participarem da expansão como produtores independentes de energia. Naturalmente isso não exclui a venda de empresas, desde que por valores compatíveis com o seu patrimônio e com o potencial de rentabilidade quando bem gerida.

\section{CONCLUSÕES}

A privatização do setor elétrico não é uma soluçáo que possa ser implementada sem uma reflexão abrangente, que obriga- toriamente inclui a revisão do modelo institucional vigente.

É preciso definir os objetivos que neste momento estão muito pouco claros, pois esse processo pode, de um lado, representar um grande aumento nos preços da energia para os consumidores em geral, e para a indústria em particular, e, por outro, exigir um Estado capaz de fiscalizar de forma eficiente e responsável empresas que prestarão serviços monopolísticos vitais ao desenvolvimento econômico.

O processo de privatização no Brasil deve se aprofundar com a promulgação da lei das concessōes e, posteriormente, com a reforma da Constituição. Cabe ainda, no entanto, esclarecer como empreender a privatização. Qual modelo organizacional deseja-se construir?

Uma estratégía a ser explorada pode ser pautada pelas seguintes fases:

- estruturação e fortalecimento de órgão normativo e regulador com forte fiscalizaçáo das empresas estatais, visando a um só tempo preparar o Estado para se relacionar com empresas privadas e ajustar as empresas estatais;

- venda seletivá de empresas, sendo que nas maiores pode-se buscar um sistema híbrido de parceria na gestão, com a admissão de sóclos privados minoritários, que possam aportar tecnologia de gestão e recursos financeiros;

- privatização paulatina das empresas de através de aumento de capital via subscrição em bolsas de valores, podendo ou não manter $51 \%$ do capital votante.

Não pode ser esquecido que a complexa estrutura de propriedade do setor, composta por empresas estatais federais, estaduais e privadas coloca a exigência de um organismo regulador competente e com poder de controlar os poderosos agentes envolvidos, protegendo o interesse público, no sentido de haver segurança e qualidade no abastecimento energético, ao mesmo tempo em que se garanta um nível de preços compatível com a realidade nacional.

\section{3}

